UDC 577.3

LBC 28.707.4

\title{
EVALUATION OF THE FUNCTIONAL CONDITION OF HUMAN BLOOD NEUTROPHILLS BASED ON THE REGISTRATION OF ACTIVE HALOGEN FORMS PRODUCTION ${ }^{1}$
}

\author{
Darya V. Grigoryeva \\ Belarus State University, Minsk, Republic of Belarus \\ Irina V. Gorudko \\ Belarus State University, Minsk, Republic of Belarus \\ Veronika E. Lutsenko \\ Belarus State University, Minsk, Republic of Belarus \\ Sergey N. Cherenkevich \\ Belarus State University, Minsk, Republic of Belarus
}

Oleg M. Panasenko

Federal Scientific and Clinical Center for Physical and Chemical Medicine, Moscow, Russian Federation

\author{
Aleksey V. Sokolov \\ Saint Petersburg State University, Saint Petersburg, Russian Federation
}

Abstract. The development of adequate methods for monitoring the functional state of neutrophils is an
urgent task due to their important role in the development of the inflammatory response. In this study, the functional
activity of neutrophils has been assessed using a complex approach, including the registration of generation of
ROS by neutrophils as a result of the functioning of the NADPH oxidase complex; degranulation of azurophilic
granules; as well as production of AFG, formed in reactions catalyzed by the enzyme azurophilic granules of
neutrophils - MPO in the presence of substrates $\left(\mathrm{H}_{2} \mathrm{O}_{2}\right.$ and halide ions).
Key words: neutrophils of human blood, production of active forms of halogens, functional activity of neutrophils.

УДК 577.3

ББК 28.707 .4

ОЦЕНКА ФУНКЦИОНАЛЬНОГО СОСТОЯНИЯ НЕЙТРОФИЛОВ КРОВИ ЧЕЛОВЕКА, ОСНОВАННАЯ НА РЕГИСТРАЦИИ ПРОДУКЦИИ АКТИВНЫХ ФОРМ ГАЛОГЕНОВ

Дарья Владимировна Григорьева

Белорусский государственный университет, г. Минск, Республика Беларусь

Ирина Владимировна Горудко

Белорусский государственный университет, г. Минск, Республика Беларусь 
Оценка функционального состояния нейтрофилов крови человека

\section{Вероника Евгеньевна Луценко}

Белорусский государственный университет, г. Минск, Республика Беларусь

\section{Сергей Николаевич Черенкевич}

Белорусский государственный университет, г. Минск, Республика Беларусь

\section{Олег Михайлович Панасенко}

ФГБУ ФНКЦ физико-химической медицины ФМБА, г. Москва, Российская Федерация

\section{Алексей Викторович Соколов}

Санкт-Петербургский государственный университет, г. Санкт-Петербург, Российская Федерация

Аннотация. Актуальной задачей является разработка адекватных способов контроля функционального состояния нейтрофилов, учитывая их важную роль в развитии воспалительной реакции. В данном исследовании была проведена оценка функциональной активности нейтрофилов с использованием комплексного подхода, включая регистрацию генерации АФК нейтрофилами в результате функционирования НАДФН-оксидазного комплекса; дегрануляции азурофильных гранул; а также продукции АФГ, образующихся в реакциях, катализируемых ферментом азурофильных гранул нейтрофилов - МПО в присутствии субстратов $\left(\mathrm{H}_{2} \mathrm{O}_{2}\right.$ и ионов галогенидов).

Ключевые слова: нейтрофилы крови человека, продукция активных форм галогенов, функциональная активность нейтрофилов.

Введение. Воспалительная реакция организма сопровождается активацией нейтрофилов, активно фагоцитирующих бактерии и собственные дефектные клетки организма. Учитывая их важную роль в развитии воспалительной реакции [4], актуальной задачей является разработка адекватных способов контроля функционального состояния этих клеток. Нейтрофилы проявляют различную функциональную активность: продукция активных форм кислорода (АФК) и галогенов (АФГ), секреция антимикробных гранулярных белков (миелопероксидазы (МПО), эластазы, катепсинов и др.), NETоз и др. [3], регистрируемую с применением различных методов. Однако помимо очевидного недостатка в дороговизне использования ряда подходов, исследователи сталкиваются также с методическими сложностями, одна из которых заключается в том, что рецепторы на поверхности нейтрофилов гликозилированы, а секретируемые данными клетками белки, проявляя лектино-подобную активность, способны по аутокринному механизму дополнительно активировать нейтрофилы.

В данной работе для оценки функциональной активности нейтрофилов нами был использован комплексный подход, включающий регистрацию генерации АФК нейтрофи- лами в результате функционирования НАДФН-оксидазного комплекса, дегрануляции азурофильных гранул, а также продукции АФГ, образующихся в реакциях, катализируемых ферментом азурофильных гранул нейтрофилов - МПО в присутствии субстратов $\left(\mathrm{H}_{2} \mathrm{O}_{2}\right.$ и ионов галогенидов).

Материалы и методы. Нейтрофилы выделяли из донорской крови, стабилизированной цитратом натрия, пугем центрифугирования с использованием декстрана Т70 и гистопака1077. Продукцию $\mathrm{H}_{2} \mathrm{O}_{2}$ оценивали флуоресцентным методом с использованием скополетина в качестве субстрата пероксидазной реакции ( возб./флуор. $=350 / 460$ нм). Образование $\mathrm{HOCl}$ и ее производных регистрировали недавно разработанным нами высокоспецифичным флуоресцентным методом с применением целестинового синего В (СВ), при окислении которого АФГ образуется флуоресцирующий продукт - гликоль

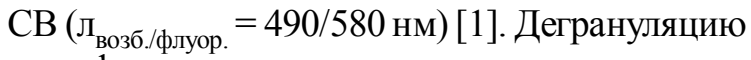
азурофильных гранул оценивали по выходу эластазы (флуоресцентным методом с использованием специфического субстрата эластазы MeO-Suc-Ala-Ala-Pro-Val-MCA, при расщеплении которого высвобождается флуорофор - аминометилкумарин ( возб./флуор. $=380 / 460$ нм)) и МПО (по пероксидазной активности фермента, регистрируемой спектрофотометрическим 
методом (л $=460$ нм) по окислению хромогенного субстрата $о$-дианизидина).

В качестве агонистов нейтрофилов использовали различные стимуляторы: хемотаксический пептид N-формил-метионил-лейцилфенилаланин (fMLP), форболовый эфир форбол 12-миристат 13-ацетат (РМА), а также растительные лектины с различной углеводной специфичностью (CAA (Caragana arborescens агглютинин), специфичный к остаткам GalNAc, Gal и GlcNAc; WGA(Triticum vulgaris агглютинин), специфичный к остаткам GlcNAc и NeuNAc; PHA-L (Phaseolus vulgaris агглютинин), специфичный к остаткам Gal, GlcNAc и Man; маннозо-специфичный Con A (Canavalia ensiformis агглютинин); SNA(Sambucus nigra агглютинин), специфичный к остаткам NeuNAc, Gal и GalNAc; SBA (Glycine max агглютинин), специфичный к остаткам GalNAc, Gal и Glc; Gal/GalNAc-специфичный PNA (Arachis hypogaea агглютинин) и GlcNAc-специфичный UDA (Urtica dioica агглютинин)).

Результаты и их обсуждение. В таблице приведены данные по влиянию всех вышеперечисленных соединений на генерацию $\mathrm{H}_{2} \mathrm{O}_{2}$, экзоцитоз эластазы и МПО из азурофильных гранул, а также продукцию $\mathrm{HOCl}$ и ее производных активированными нейтрофилами.
Известно, что для экзоцитоза содержимого азурофильных гранул и, следовательно, продукции АФГ нейтрофилами, при действии на клетки растворимых стимулов (лектины, fMLP), активирующих нейтрофилы по рецептор-зависимому механизму, необходима предварительная инкубация нейтрофилов с цитохалазином B (cyt B), препятствующим полимеризации фибриллярного актина цитоскелета [6]. РМА, являясь липофильным соединением, легко проникает в клетки и инициирует респираторный взрыв и дегрануляцию нейтрофилов [2] и без помощи суt $\mathrm{B}$.

Как показано в таблице, fMLP и PMA вызывали продукцию $\mathrm{H}_{2} \mathrm{O}_{2}$ и экзоцитоз содержимого азурофильных гранул нейтрофилов. Наличие во внеклеточной среде МПО, $\mathrm{H}_{2} \mathrm{O}_{2}$ и $\mathrm{Cl}^{-}$предполагает образование $\mathrm{HOCl}$ и ее производных, что и было продемонстрировано нами с помощью недавно разработанного флуоресцентного метода, основанного на регистрации во внеклеточной среде увеличения интенсивности флуоресценции гликоля $\mathrm{CB}$, образующегося при окислении $\mathrm{CB} \mathrm{HOCl}$ и еe производными.

Далее нами был проведен скрининг растительных лектинов, которые, как известно, способны специфически связываться с различными гликозилированными структурами на поверхности нейтрофилов, что приводит к за-

Влияние агонистов различной природы на генерацию $\mathrm{H}_{2} \mathrm{O}_{2}$ (скорость окисления скополетина), экзоцитоз эластазы и МПО, а также продукцию HOCI и ее производных (скорость образования гликоля СВ) нейтрофилами

\begin{tabular}{|l|c|c|c|c|}
\hline $\begin{array}{c}\text { Активатор, концентра- } \\
\text { ция }\end{array}$ & $\begin{array}{c}\text { Скорость окисле- } \\
\text { ния скополетина, } \\
\text { усл. ед./мин }\end{array}$ & $\begin{array}{c}\text { Активность эла- } \\
\text { стазы, } \\
\text { усл. ед./мин }\end{array}$ & $\begin{array}{c}\text { Активность МПО, } \\
\Delta D_{460} / \text { мин }\end{array}$ & $\begin{array}{c}\text { Скорость образо- } \\
\text { вания гликоля СВ, } \\
\text { усл. ед./мин }\end{array}$ \\
\hline $\begin{array}{l}\text { Контроль (без актива- } \\
\text { тора) }\end{array}$ & 0 & $0,19 \pm 0,03$ & $0,013 \pm 0,0025$ & 0 \\
\hline fMLP, 1 мкM & $24,33 \pm 3,95^{*}$ & $7,17 \pm 0,51^{*}$ & $0,025 \pm 0,0013^{*}$ & $0,029 \pm 0,004^{*}$ \\
\hline PMA, 50 нМ & $22,29 \pm 1,90^{*}$ & $8,05 \pm 1,07^{*}$ & $0,015 \pm 0,0002^{*}$ & $0,021 \pm 0,004^{*}$ \\
\hline CAA, 100 мкг/мл & $2,01 \pm 0,38^{*}$ & $0,34 \pm 0,03^{*}$ & $0,060 \pm 0,0095^{*}$ & $0,032 \pm 0,009^{*}$ \\
\hline WGA, 50 мкг/мл & $1,20 \pm 0,18^{*}$ & $3,59 \pm 0,46^{*}$ & $0,045 \pm 0,0068^{*}$ & $0,016 \pm 0,003^{*}$ \\
\hline PHA-L, 100 мкг/мл & $1,11 \pm 0,37^{*}$ & $0,58 \pm 0,03^{*}$ & $0,058 \pm 0,0088^{*}$ & $0,014 \pm 0,001^{*}$ \\
\hline Con A, 100 мкг/мл & $0,98 \pm 0,21^{*}$ & $0,72 \pm 0,01^{*}$ & $0,0084 \pm 0,0034$ & $0,014 \pm 0,005^{*}$ \\
\hline SNA, 100 мкг/мл & $1,31 \pm 0,08^{*}$ & $0,09 \pm 0,11$ & $0,023 \pm 0,0057$ & 0 \\
\hline SBA, 100 мкг/мл & $0,99 \pm 0,17^{*}$ & $0,18 \pm 0,03$ & $0,012 \pm 0,0062$ & 0 \\
\hline PNA, 100 мкг/мл & $0,78 \pm 0,11^{*}$ & $0,15 \pm 0,05$ & $0,016 \pm 0,009$ & 0 \\
\hline UDA, 100 мкг/мл & $0,36 \pm 0,10^{*}$ & $0,02 \pm 0,13$ & $0,0031 \pm 0,0017$ & 0 \\
\hline
\end{tabular}

Примечание. Данные представлены как среднее \pm среднеквадратичная ошибка среднего, вычисленные по результатам 7 независимых экспериментов. *p<0,05 по сравнению с ответом клеток в отсутствие стимулятора. 
пуску ряда процессов внутриклеточной сигнализации и, в конечном итоге, к активации клеток [5]. Как видно из данных, представленных в таблице, все используемые в данной работе лектины стимулировали активацию НАДФН-оксидазы и, следовательно, продукцию $\mathrm{H}_{2} \mathrm{O}_{2}$ нейтрофилами, однако скорость окисления скополетина различалась для разных лектинов. Экзоцитоз МПО, регистрируемый по пероксидазной активности фермента в супернатантах активированных нейтрофилов, был достоверно выше по сравнению с контролем только после инкубации клеток с САА, WGA и PHA-L. При исследовании продукции $\mathrm{HOCl}$ и ее производных увеличение интенсивности флуоресценции гликоля СВ в суспензии нейтрофилов было зарегистрировано не только при действии лектинов, вызывающих экзоцитоз МПО, но также и при действии Con A. При последующем исследовании дегрануляции азурофильных гранул по регистрации во внеклеточной среде нейтрофильной эластазы, было установлено, что Con А вызывает экзоцитоз эластазы, а значит и других компонентов азурофильных гранул, включая МПО. Учитывая тот факт, что в состав молекулы МПО входят $5 \mathrm{~N}$-гликанов, представленных в основном структурами с высоким содержанием маннозы, отсутствие экзоцитоза МПО при действии Con A может быть ассоциировано со связыванием высвобождающейся из азурофильных гранул нейтрофилов МПО с уже находящимся на поверхности нейтрофилов Con А и последующей ее преципитацией вместе с клетками.

Заключение. На основании полученных данных можно заключить, что при необходимости универсальной оценки функциональной активности нейтрофилов наиболее рациональным будет применение флуоресцентного ме- тода с использованием целестинового синего В, позволяющего оценивать продукцию клетками гипогалоидных кислот и их производных, необходимыми условиями образования которых являются высвобождение МПО в результате дегрануляции и наличие ее субстрата $-\mathrm{H}_{2} \mathrm{O}_{2}$, образующегося при респираторном взрыве нейтрофилов.

\section{ПРИМЕЧАНИЕ}

1 Работа поддержана грантами РФФИ(17-0400530 и 18-515-00004) и БРФФИ(Б18Р-058).

\section{СПИСОК ЛИТЕРАТУРЫ}

1. Kinetic method for assaying the halogenating activity of myeloperoxidase based on reaction of celestine blue $B$ with taurine halogenamines /A. V. Sokolov [et al.] // Free Radic. Res. - 2015. - Vol. 49 (6). - P. 777-789.

2. Nagaji, J. The role of protein kinase $C$ and $\left[\mathrm{Ca}^{2+}\right]_{\mathrm{i}}$ in superoxide anion synthesis and myeloperoxidase degranulation of human neutrophils / J. Nagaji // Kurume Med. J. - 1999. - Vol. 46 (3-4). P. $157-162$.

3. Neutrophil function: from mechanisms to disease / B. Amulic [et al.] //Annu. Rev. Immunol. 2012. - Vol. 49 (9). - P. 459-489.

4. Neutrophil function in inflammation and inflammatory diseases / H. L. Wright [et al.] // Rheumatology (Oxford). - 2010. - Vol. 49 (9). P. 1618-1631.

5. Pereira-da-Silva, G. Neutrophil activation induced by plant lectines: modulation of inflammatory processes / G. Pereira-da-Silva, F. C. Carvalho, M. C. Roque-Barreria // Inflamm. Allergy Drug Targets. - 2012. - Vol. 11 (6). - P. 433-441.

6. The actin cytoskeleton regulates exocytosis of all neutrophil granule subsets / N. R. Jog [et al.] // Am. J. Physiol. Cell Physiol.-2007.-Vol. 292 (5). -P. 1690-1700.

\section{Information about the Authors}

Darya V. Grigoryeva, Senior Researcher, Department of Biophysics, Research Laboratory of Biophysics and Biotechnology, Belarus State University, Prosp. Nezavisimosti, 4, 220030 Minsk, Republic of Belarus, dargr@tut.by.

Irina V. Gorudko, Leading Researcher, Department of Biophysics, Research Laboratory of Biophysics and Biotechnology, Belarus State University, Prosp. Nezavisimosti, 4, 220030 Minsk, Republic of Belarus. 
Veronika E. Lutsenko, Department of Biophysics, Research Laboratory of Biophysics and Biotechnology, Belarus State University, Prosp. Nezavisimosti, 4, 220030 Minsk, Republic of Belarus.

Sergey N. Cherenkevich, Doctor of Sciences (Biology), Professor, Department of Biophysics, Research Laboratory of Biophysics and Biotechnology, Belarus State University, Prosp. Nezavisimosti, 4, 220030 Minsk, Republic of Belarus.

Oleg M. Panasenko, Doctor of Sciences (Biology), Head of Department of Biophysics, Federal Scientific and Clinical Center for Physical and Chemical Medicine, Malaya Pirogovskaya St., 1a, 119435 Moscow, Russian Federation, info@rcpcm.org.

Aleksey V. Sokolov, Senior Lecturer, Faculty of Dentistry and Medical Technology, Saint Petersburg State University, Universitetskaya Emb., 7-9, 199034 Saint Petersburg, Russian Federation, biochemsokolov@gmail.com.

\section{Информация об авторах}

Дарья Владимировна Григорьева, старший научный сотрудник НИЛ биофизики и биотехнологии, Белорусский государственный университет, пр. Независимости, 4, 220030 г. Минск, Республика Беларусь, dargr@tut.by.

Ирина Владимировна Горудко, ведущий научный сотрудник НИЛ биофизики и биотехнологии, Белорусский государственный университет, пр. Независимости, 4, 220030 г. Минск, Республика Беларусь.

Вероника Евгеньевна Луценко, кафедра биофизики, НИЛ биофизики и биотехнологии, Белорусский государственный университет, пр. Независимости, 4, 220030 г. Минск, Республика Беларусь.

Сергей Николаевич Черенкевич, доктор биологических наук, профессор, кафедра биофизики, НИЛ биофизики и биотехнологии, Белорусский государственный университет, пр. Независимости, 4, 220030 г. Минск, Республика Беларусь.

Олег Михайлович Панасенко, доктор биологических наук, заведующий отделом биофизики, ФГБУ ФНКЦ физико-химической медицины ФМБА, ул. Малая Пироговская, 1a, 119435 г. Москва, Российская Федерация, info@rcpcm.org.

Алексей Викторович Соколов, старший преподаватель, факультет стоматологии и медицинских технологий, Санкт-Петербургский государственный университет, Университетская наб., 7-9, 199034 г. Санкт-Петербург, Российская Федерация, biochemsokolov@gmail.com. 